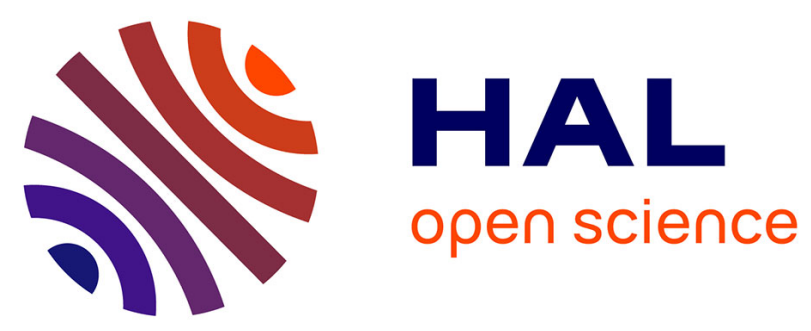

\title{
BRILLOUIN SCATTERING DETERMINATION OF THE ELASTIC MODULI OF AgGaS2 AND THEIR INFLUENCE ON THE ANALYSIS OF THE OPTICAL PHONON DATA
}

\author{
G. Holah, M. Grimsditch
}

\section{To cite this version:}

G. Holah, M. Grimsditch. BRILLOUIN SCATTERING DETERMINATION OF THE ELASTIC MODULI OF AgGaS2 AND THEIR INFLUENCE ON THE ANALYSIS OF THE OPTICAL PHONON DATA. Journal de Physique Colloques, 1975, 36 (C3), pp.C3-185-C3-188. 10.1051/jphyscol:1975334 . jpa-00216304

\section{HAL Id: jpa-00216304 https://hal.science/jpa-00216304}

Submitted on 1 Jan 1975

HAL is a multi-disciplinary open access archive for the deposit and dissemination of scientific research documents, whether they are published or not. The documents may come from teaching and research institutions in France or abroad, or from public or private research centers.
L'archive ouverte pluridisciplinaire HAL, est destinée au dépôt et à la diffusion de documents scientifiques de niveau recherche, publiés ou non, émanant des établissements d'enseignement et de recherche français ou étrangers, des laboratoires publics ou privés. 


\title{
BRILLOUIN SCATTERING DETERMINATION OF THE ELASTIC MODULI OF AgGaS $_{2}$ AND THEIR INFLUENCE ON THE ANALYSIS OF THE OPTICAL PHONON DATA (*)
}

\author{
G. D. HOLAH $(* *)$ and M. GRIMSDITCH \\ Physics Department, Purdue University, West Lafayette, Indiana 47907, USA
}

\begin{abstract}
Résumé. - Les modules d'élasticité de $\mathrm{AgGaS}_{2}$ ont étẻ déterminés par diffusion Brillouin. On trouve qu'ils sont inférieurs à ceux de l'analogue binaire $\mathrm{ZnS}$. Il est discuté en détail l'intérêt que peut avoir cette observation pour attribuer des coordonnécs normales aux différents phonons optiques observés.

L'importance des électrons d de la configuration de $\mathrm{Ag}^{*}$ dans l'analyse des phonons optiques est également prise en considération. Sur la base de ces discussions, on suggère que les attributions précédentes peuvent être erronées pour les modes de fréquences élevécs et une nouvelle attribution est proposée.
\end{abstract}

Abstract. - The elastic moduli of $\mathrm{AgGaS}_{2}$ have been determined using laser Brillouin scattering. It is found that they are lower than those of the binary analogue $\mathrm{ZnS}$. The relevance of this overall decrease in helping to assign normal mode coordinates to observed optical phonon frequencies is discussed in detail. The importance of the d-electron configuration of the $\mathrm{Ag}^{-}$on the analysis of optical phonons is also considered. On the basis of the discussions it is proposed that the previous analyses may have been in error for high frequency modes and an alternative assignment is suggested.

1. Introduction. - The I-III-VI $I_{2}$ and II-IV-V ternary semiconductors, which form in the chalcepyrite structure, have been the subject of a number of recent investigations into their lattice vibrational modes $[1-10]$. With the exception of the results discussed here the data have been obtained using Raman scattering or infrared reflectivity, no previous determination of the elastic moduli for any chalcopyrite has been made. Although early work on $\mathrm{ZnSiP}_{2}^{3}$ suggested that the main polar modes consisted of, for example, $Z n$ vibrating in antiphase to $P$, with $S i$ taking no part and $\mathrm{Si}$ against $\mathrm{P}$ with $\mathrm{Zn}$ taking no part, it is now generally accepted that the main polar mode should consist of the whole cation sublattice moving against the anion sublattice. It has been shown $[6,11]$ that due to the close similarity between the chalcopyrite and sphalerite (zincblende) lattice important relations between the two structures may be obtained which assist in the interpretation of the phonon spectra.

Due to the complexity of the optical phonon structure of the chalcopyrites, the assignment of specific atomic displacements to observed frequencies is not straightforward and for the I-III-VI $\mathrm{VI}_{2}$ compounds additional ambiguities may arise due to the delocalized d-electron configuration of the $\mathrm{Ag}^{+}$ions. A complete analysis is further hindered by the conflicting data

(*) Supported by N. S. F. through Grant Nos. 32001-A1, GH-43409 and MRL Program GH 33574-A3.

(**) Address after Sept. Ist, Physics Dept., Heriot-Watt University, Edinburgh. which occurs for some modes. The present paper attempts to clarify some of the problems by making use of the consequences of the change in elastic constants of $\mathrm{AgGaS}_{2}$ relative to $\mathrm{ZnS}$. Some of the discussion will have relevance to the phonon spectra of II-IV-V $V_{2}$ compounds, however the main emphasis will be on $\mathrm{AgGaS}_{2}$ and to a lesser extent $\mathrm{CuGaS}_{2}$.

2. Experimental. - The structure of $\mathrm{AgGaS}_{2}$ is shown in figure 1 and it can be seen that the tetrahedral coordination is very similar to zincblende. If the $\mathrm{Ag}$ and $\mathrm{Ga}$ sites were indistinguishable then the two structures would be identical. Since Ag and Ga belong to different columns in the periodic table their bondings to the sulfur ions are different, the more covalent Ga-S bond being stiffer. This moves the sulfur atoms away from a symmetric tetrahedral position to one nearer the trivalent $\mathrm{Ga}$ ions. Furthermore, there is tetragonal compression with $c / a=1.789$ [11]. The point group for chalcopyrite is $72 \mathrm{~m}$ and the character table is shown in table I. Since there are two molecular units per unit primitive cell there are 24 normal modes of vibration. Brillouin scattering from acoustic phonons of $\mathrm{AgGaS}_{2}$ has been performed and the data analyzed to yield the clastic moduli, $c_{11}, c_{33}, c_{44}, c_{66}, c_{12}$ and $c_{13}$. The scattering tensors appropriate to $42 \mathrm{~m}$ have been given elsewhere [13] and will not be repeated here.

A Coherent Radiation argon laser with an etalon to produce a single axial mode was used as the exciting source. The scattered radiation, from both right-angle 


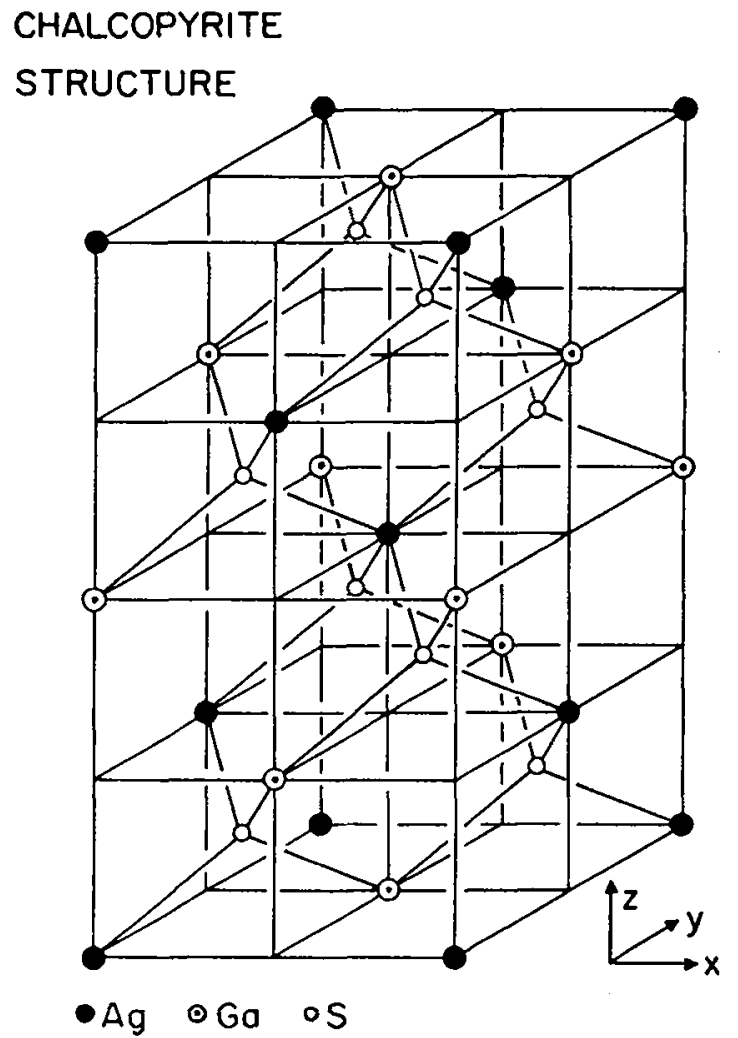

Fig. 1. - Structure of $\mathrm{AgGaS}_{2}$.

and backscattering geometries, was analyzed using a triple-passed piezoelectrically-scanned Fabry-Pèrot interferometer. An S-20 photomultiplier (RCA 7265) was used together with photon-counting electronics. For further discussion of the experimental details the reader is referred to reference [13]. Typical spectra are shown in figure 2.

3. Discussion. - As indicated previously there are similarities between the zincblende and chalcopyrite structures which leads to a number of extremely useful correlations in their lattice vibrational spectra. It can easily be shown that modes corresponding to $\Gamma(0,0,0), \mathrm{X}(0,0,1), \mathrm{W}^{\mathrm{a}}\left(1,0, \frac{1}{2}\right)$ and $\mathrm{W}^{\mathrm{b}}\left(0,1, \frac{1}{2}\right)$ of zincblende become zone center modes of chalcopyrite. This folding-back of zincblende dispersion curves is similar to the folding back along the [111] direction of zincblende $\mathrm{ZnS}$ to give the dispersion curves of

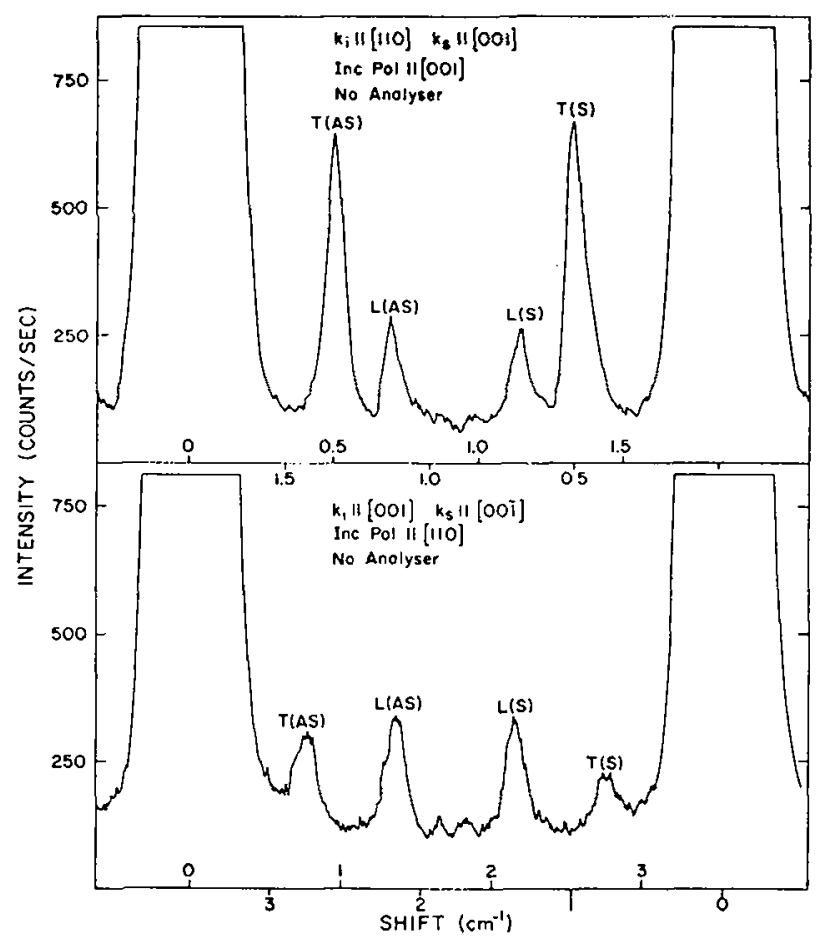

Frg. 2. - Brillouin Spectra of $\mathrm{AgGaS}_{2}$. Upper curve rightangle scattering. Lower curve backscattering.

wurzite $\mathrm{ZnS}$. Immediately therefore, since the normal mode coordinates for zincblende are known, we have a good basis for the "normal mode " coordinates of chalcopyrite. Additionally since the force constants and reduced masses for the isoelectronic analogues may be similar, then judicious use of the phonon dispersion curves of zincblende should help to assign observed frequencies to the atomic displacements. The II-VI $\mathrm{ZnS}$ is the nearest binary analogue to $\mathrm{CuGaS}_{2}$ and $\mathrm{AgGaS}_{2}$. Since $\mathrm{Cu}$ and $\mathrm{Ga}$ lie each side of $\mathrm{Zn}$ in the periodic table their masses and electron configurations are similar, and we should expect the greatest correlation between $\mathrm{ZnS}$ and $\mathrm{CuGaS}_{2}$. We may also expect some indications from $\mathrm{ZnS}$ to hold for $\mathrm{AgGaS}_{2}$.

The agreement between the various determinations $[6,7]$ of optical phonon energies and symmetries is, with the exception of the $B_{1}$ modes, quite good for $\mathrm{AgGaS}_{2}$. Unfortunately there seems to be some discrepancies in the available data on $\mathrm{CuGaS}_{2}[7,8]$.

\section{TABLE I}

Character table for point group $42 \mathrm{~m}$

\begin{tabular}{|c|c|c|c|c|c|c|c|c|c|}
\hline & $\mathrm{E}$ & $2 \mathrm{~S}_{4}$ & $\mathrm{C}_{2}$ & $2 C_{2}^{\prime}$ & $2 \sigma_{d}$ & Symmetry & Activity & Optic & Acoustic \\
\hline $\bar{A}$ & 1 & -1 & - & - & -1 & $x^{2}+\overline{v^{2}}, z^{2}$ & $\overline{\mathrm{R}}$ & - & \\
\hline $\mathrm{A}_{2}$ & 1 & 1 & 1 & -1 & -1 & & inactive & 2 & \\
\hline $\mathrm{B}_{1}$ & 1 & -1 & 1 & 1 & -1 & $x^{2}-y^{2}$ & $\mathrm{R}$ & 3 & \\
\hline $\mathrm{B}_{2}$ & 1 & -1 & 1 & -1 & 1 & $x y ; z$ & $\mathbf{R}$; ir & 3 & 1 \\
\hline $\mathrm{E}$ & 2 & 0 & -2 & 0 & 0 & $x z, y z ; x, y$ & $\mathbf{R}$; ir & 6 & 1 \\
\hline
\end{tabular}


The assignments for the polar modes of $\mathrm{AgGaS}_{2}$ were mainly based on the Coulomb splitting of the modes and it is the intention on the paper to suggest that this argument may have been in error and to derive new assignments for $\mathrm{AgGaS}_{2}$ and $\mathrm{CuGaS}_{2}$.

\section{TABLE II}

Comparison of elastic moduli of cubic $\mathrm{ZnS}$ and tetragonal $\mathrm{AgGaS}_{2}$, units of $10^{\prime \prime}$ dynes $/ \mathrm{cm}^{2}$

$\begin{array}{lcc}\text { Elastic moduli } & \mathrm{ZnS}[15] & \mathrm{AgGaS}_{2} \\ c^{11} & - & - \\ c_{33} & 10.46 & 8.79 \pm 0.05 \\ c_{44} & & 7.58 \pm 0.05 \\ c_{66} & 4.613 & 2.41 \pm 0.05 \\ c_{12} & & 3.08 \pm 0.05 \\ c_{13} & 6.53 & 5.84 \pm 0.05 \\ & & 5.92 \pm 0.06\end{array}$

Since the same interatomic force constants are responsible for the elastic properties and the optical phonon properties of a given compound it is clear that a determination of the elastic moduli of $\mathrm{AgGaS}_{2}$ should prove useful in analyzing optical phonon data. The results for $\mathrm{AgGaS}_{2}$ are shown in table II along with those of $\mathrm{ZnS}$, it is clear that in each case they are lower than the corresponding values for $\mathrm{ZnS}$. If the two compounds had identical structures and reduced masses then it would be relatively straightforward to state that the lower elastic constants indicate lower optical phonon energies. This has been elegantly demonstrated by neutron scattering data on $\alpha$-Sn, InSb and CdTe [14], an isoelectronic series of semiconductors with zincblende structure and almost equal reduced masses. As the ionicity of the bonding increases, i. e. $\alpha-\mathrm{Sn} \rightarrow \mathrm{CdTe}$, the elastic moduli and optical phonon frequencies decrease. Although there are mass differences between $\mathrm{AgGaS}_{2}$ and $\mathrm{ZnS}$, the lower elastic suggests that the force constants and hence the optical phonon energies should also be lower. An increase in ionicity is also suggested.

A further indication of force constant differences between $\mathrm{AgGaS}_{2}$ and $\mathrm{ZnS}$ may be obtained from the frequency of the normal mode in which only the sulfur ion is vibrating. In $\mathrm{ZnS}$ this is the $\mathrm{W}_{1}(\mathrm{LO})$ mode at $320 \mathrm{~cm}^{-1}$ [17] and for $\mathrm{AgGaS}_{2}$ the corresponding mode is the $A_{1}$ at $295 \mathrm{~cm}^{-1}$. This suggests a lower effective force constant. For $\mathrm{CuGaS}_{2}$ the $A_{1}$ is at $312 \mathrm{~cm}^{-1}$.

The ionicity of $\mathrm{AgGaS}_{2}$ has been calculated using a bond charge model [16] to evaluate the bond ionicity of the two types of bonds. The average of the two bonds, $f_{i}=0.719$ is greater than that of $\mathrm{ZnS}, f_{i}=0.621$. If we take the ratio of static dielectric constant to electronic dielectric constant, $\varepsilon_{s} / \varepsilon_{\infty}$, as an indication of ionicity then again $\mathrm{AgGaS}_{2}$ is higher than $\mathrm{ZnS}$, at least for the E modes, $\varepsilon_{\mathrm{s}} / \varepsilon_{\infty}($ E modes $)=1.7 \varepsilon_{\mathrm{s}} / \varepsilon_{\infty}\left(\mathrm{B}_{2}\right.$ modes $)=1.5$ and $\mathrm{ZnS}=1.63$.
The conclusion we tentatively draw from the above discussion is that the $\Gamma_{15}$ mode of $\mathrm{ZnS}$ should be at a higher frequency than the corresponding $\mathrm{AgGaS}_{2}$ mode.

If we examine the Raman and infrared data of $\mathrm{AgGaS}_{2}$ the only $\mathrm{E}$ and $\mathrm{B}_{2}$ modes which are almost equal and lower than $\Gamma_{15}$ of $\mathrm{ZnS}\left(273 \mathrm{~cm}^{-1}\right)$ are the $\mathrm{E}$ mode at $223 \mathrm{~cm}^{-1}$ and the $\mathrm{B}_{2}$ at $214 \mathrm{~cm}^{-1}$. Since $\Gamma_{15}$ is the polar mode of $\mathrm{ZnS}$ we might expect the modes derived from this also to be most polar. This is found to be the case for the $B_{2}$ mode but not the $E$ mode. The answer to the low Coulomb splitting of this E mode may perhaps lie with the d-electron configuration of the $\mathrm{Ag}^{+}$ions. In the noble metals such as $\mathrm{Ag}$ and $\mathrm{Cu}$ the d-electrons are delocalized unlike the tightly bound d-electrons of $\mathrm{Zn}$. This fact has been shown to have important consequences for the lattice vibrations.

Levine [16] has shown that it is necessary to include d-electron effects to calculate a reasonable value for the ionicity of $\mathrm{Cu}_{2} \mathrm{O}$. Also the same author has taken the number of valence electrons of $\mathrm{Ag}$ and $\mathrm{Cu}$ to be 11 and not 1 in his calculations for nonlinear susceptibilities and bond ionicity. Further evidence for the effect of d-clectrons can be seen in a comparison of the phonon dispersion curves of $\mathrm{AgCl}$ and $\mathrm{RbCl}$ [18]. There are a number of important differences, the $\mathrm{Ag}$ halide is significantly more ionic with a large Coulomb splitting, although the force constants are not too dissimilar, $\omega_{\mathrm{IO}}(\mathrm{AgCl})$ and $\omega_{\mathrm{TO}}(\mathrm{AgCl})$ both show substantial dispersion over the Brillouin zone, whilst tor $\mathrm{RbCl} \omega_{\text {ro }}$ is almost dispersionless and $\omega_{\mathrm{LO}}$ shows the usual decrease as the wavevector $q$ approaches 1 . Along [001] $\omega_{\mathrm{LO}}(\mathrm{AgCl})$ has almost the same value of $q=0$ as at $q=1$, and $\omega_{\mathrm{TO}}$ at $q=1$ is more than $20 \%$ higher than $\omega_{\text {TO }}$ at the zone center. Although these halides have rocksalt structure we may imagine that similar anomalies may occur for a zincblende compound containing Ag.

Another factor introduced by the d-electron configuration is that the effective charge of $\mathrm{Ag}^{+}$is now 11 and since the Coulomb splitting of $\mathrm{AgGaS}_{2}$ modes derived from zone boundary modes of zincblende is due to the differences in the cation effective charges we find the $\Delta Z$ for Ag-Ga is $11-3=8$ instead of -2 . Therefore we might expect an anomalously large Coulomb splitting for modes in which $\mathrm{Ag}$ vibrates against $\mathrm{Ga}$. From the symmetry coordinates of reference [6] these are the $\mathrm{B}_{2}$ from $\mathrm{W}_{2}$ and the $\mathrm{E}$ modes from $\mathrm{W}_{3}$ and $\mathrm{W}_{4}$.

Based upon these arguments we would tentatively suggest the assignments for the observed frequencies of $\mathrm{AgGaS}_{2}$ and $\mathrm{CuGaS}_{2}$ to be as shown in figure 3. It is clear that there is little problem in assigning the modes which correspond to the zone boundary acoustic phonons of $\mathrm{ZnS}$. In each case the frequency of the chalcopyrite phonon is lower than $\mathrm{ZnS}$ with the exception of the $\mathrm{LA}(\mathrm{X})$ mode which corresponds to a $\mathrm{CuGaS}_{2} \mathbf{B}_{1}$ phonon of the same energy. There is also no question of the $A_{1}$ modes coming from $W_{2}$ of $\mathrm{ZnS}$ at $320 \mathrm{~cm}^{-1}$, being $312 \mathrm{~cm}^{-1}$ in $\mathrm{CuGaS}_{2}$ and $295 \mathrm{~cm}^{-1}$ 


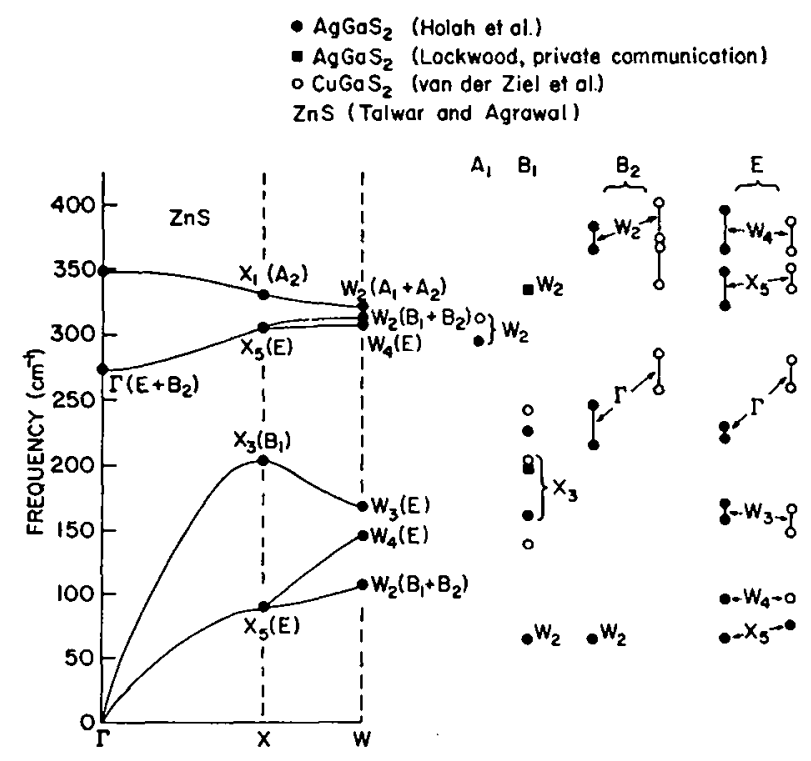

FIG. 3. - Phonon dispersion curves for $\mathrm{ZnS}$ and assignments. of phonon frequencies for $\mathrm{AgGaS}_{2}$. Symmetry species of the $\mathrm{AgGaS}_{2}$ modes are given in the brackets. Assignments for $\mathrm{CuGaS}_{2}$ are also shown.

in $\mathrm{AgGaS}_{2}$. This implies a lowering of force constants from $\mathrm{ZnS}$ to $\mathrm{CuGaS}_{2}$ to $\mathrm{AgGaS}_{2}$.

One of the problems with producing a model is that there is considerable conflict in the $B_{2}$ modes of $\mathrm{CuGaS}_{2}$, the Raman data suggests a mode at $259 \mathrm{~cm}^{-1}$, whilst no such mode is given in the infrared data. If we accept the Raman data a trend appears which suggests that the $\Gamma$ mode of $\mathrm{ZnS}$ at $273 \mathrm{~cm}^{-1}$, becomes $\mathrm{E}$ modes at $260 \mathrm{~cm}^{-1}$ and $220 \mathrm{~cm}^{-1}, B_{2}$ modes at $259 \mathrm{~cm}^{-1}$ and $214 \mathrm{~cm}^{-1}$ for $\mathrm{CuGaS}_{2}$ and $\mathrm{AgGaS}_{2}$ respectively. The main drawback to this assignment is the small Coulomb splitting of the $220 \mathrm{~cm}^{-1} \mathrm{E}$ mode in $\mathrm{AgGaS}_{2}$. The correlations between the remaining high frequency $E$ and $B_{2}$ phonons would seem to be reasonable. The correlations for the $\mathrm{B}_{1}$ modes for $\mathrm{AgGaS}_{2}$ are also reasonable but not good for $\mathrm{CuGaS}_{2}$. There is clearly a need for further work on $\mathrm{CuGaS}_{2}$ to establish the Raman spectra and infrared spectra with a higher level of confidence.

4. Summary. - We have measured the elastic moduli of $\mathrm{AgGaS}_{2}$ using Brillouin scattering. In all cases the magnitudes of the moduli were lower than those of the binary analogue $\mathrm{ZnS}$. This suggests, along with other evidence, that the force constants are lower for $\mathrm{AgGaS}_{2}$ and hence optical phonon energies should be lower for the modes corresponding to the $\Gamma$ phonon of $\mathrm{ZnS}$. It has been suggested therefore that the previous normal mode assignments may be in error. d-electron effects of the $\mathrm{Ag}^{+}$ion have been used to explain why the frequencies of the other polar modes are higher than the zone boundary modes of $\mathrm{ZnS}$ and why the Coulomb splitting of these modes is higher than may have been expected. No adequate explanation for the low Coulomb splitting of the $\mathrm{E}$ mode at $220 \mathrm{~cm}^{-1}$ is given, it remains for a detailed analysis to be made.

\section{References}

[1] Miller, A., Holah, G. D., Clark, W., J. Phys. Chem. Solids 35 (1974) 685.

[2] Bettini, M., Miller, A., Phys. Stat. Sol. b 66 (1974) 579.

[3] Kaminow, I, P., Buehler, E., Wernick, J. H., Phys, Rev. B 2 (1970) 960.

[4] Holah, G. D., J. Phys. C. : Solid State 5 (1972) 1893.

[5] Bettini, M., Bauhofer, W., Cardona, M., Nitsche, R., Phys. Stat. Sol. b 63 (1974) 641.

[6] Holah, G. D., Webi, J. S., Montgomery, H., J. Phys. $C$ : Solid State 7 (1974) 3875.

[7] Van der Ziel, J. P., MeiXnier, A. E., Kaspar, H. M., Ditzenberger, J. A., Phys. Rev. B 9 (1974) 4286.

[8] BaArs, J., Koschel, W. H., Solid State Commun. 11 (1972) 1513.

[9] Koschel, W. H., Hohler, V., Räuber, A., BaArs, J., Solid State Commun. 13 (1973) 1011.
[10] Holah, G. D., Montgomerx, H., Webb, J. S., Proc. Int. Conf. on Physics of Semiconductors (Stuttgart) 1974,316.

[11] Karavaev, G. F., Poplavinoi, A. C., Tyuterev, B. G., Izv. Vuzov. 10 (1970) 42.

[12] Brandt, G., Räuber, A., Schneider, J., Solid State Commun. 12 (1973) 481.

[13] Grimsuitch, M., Holah, G. D., Phys. Rev. B to be published.

[14] Rowe, J. M., Nicklow, R. M., Price, D. L., Zanio, K., Phys. Rev, B 10 (1974) 671.

[15] Berlincourt, D., Jafre, H., Shiozawa, L. R., Phys. Rev. 129 (1963) 1009.

[16] Levine, B. F., Phys. Rev. B 7 (1973) 2591.

[17] Talwar, D. N., Agrawal, Bal. K., Phys. Stat. Sol. B 64 (1974) 71.

[18] Fischer, K., Bilz, H., Haberkorn, R., Weber, W., Phys. Stat. Sol. (b) 54 (1972) 285. 